\title{
Understanding the key issues in the treatment of uncontrolled persistent asthma with type 2 inflammation
}

\author{
William W. Busse ${ }^{1}$, Monica Kraft ${ }^{2}$, Klaus F. Rabe ${ }^{3,4}$, Yamo Deniz ${ }^{5}$, Paul J. Rowe ${ }^{6}$, Marcella Ruddy ${ }^{5}$ and \\ Mario Castro ${ }^{7}$
}

${ }^{1}$ UW Allergy, Pulmonary and Critical Care Medicine, University of Wisconsin School of Medicine and Public Health, Madison, WI, USA. ${ }^{2}$ University of Arizona Health Sciences Center, Tucson, AZ, USA. ${ }^{3}$ LungenClinic Grosshansdorf (member of the German Center for Lung Research, DZL), Airway Research Center North (ARCN), Grosshansdorf, Germany. ${ }^{4}$ Christian-Albrechts University (member of the German Center for Lung Research, DZL), Airway Research Center North (ARCN), Kiel, Germany. ${ }^{5}$ Regeneron Pharmaceuticals, Inc., Tarrytown, NY, USA. ${ }^{6}$ Sanofi, Bridgewater, NJ, USA. ${ }^{7}$ University of Kansas School of Medicine, Kansas City, KS, USA.

Corresponding author: William W. Busse (wwb@medicine.wisc.edu)



This version is distributed under the terms of the Creative Commons Attribution Non-Commercial Licence 4.0. For commercial reproduction rights and permissions contact permissions@ersnet.org

Received: 4 Sept 2020 Accepted: 21 Dec 2020

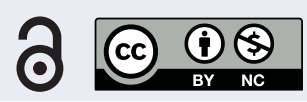

Shareable abstract (@ERSpublications)

This review covers the pathophysiology of type 2 inflammation in asthma, its influence on type 2 comorbidities, and ways in which type 2 biomarkers can be harnessed to improve diagnosis and further personalise treatments in the age of biologic medicines https://bit.ly/2MSOI2O

Cite this article as: Busse WW, Kraft M, Rabe KF, et al. Understanding the key issues in the treatment of uncontrolled persistent asthma with type 2 inflammation. Eur Respir J 2021; 58: 2003393 [DOI: 10.1183/13993003.03393-2020].

\section{Abstract}

Asthma is a complex respiratory disease that varies in severity and response to treatment. Several asthma phenotypes with unique clinical and inflammatory characteristics have been identified. Endotypes, based on distinct molecular profiles, help to further elucidate the heterogeneity within asthma. Type 2 inflammation, involving both the innate (type 2 innate lymphoid cell) and adaptive (T-helper type 2 cells) immune systems, underpins the complex pathophysiology of chronic inflammation in asthma, as well as the presence of comorbid disease (e.g. chronic rhinosinusitis with nasal polyps, allergic rhinitis and atopic dermatitis). Type 2 inflammation is characterised by upregulation of the type 2 cytokines interleukin (IL)-4, IL-5 and IL-13, IgE-mediated release of immune mediators and dysfunction of epithelial or epidermal barriers. Targeting these key proximal type 2 cytokines has shown efficacy in recent studies adopting a personalised approach to treatment using targeted biologics. Elevated levels of biomarkers downstream of type 2 cytokines, including fractional exhaled nitric oxide, serum IgE and blood and sputum eosinophils, have been linked to mechanisms involved in type 2 inflammation. They have the potential to aid diagnosis, and to predict and monitor response to treatment. The objective of this review is to summarise the current understanding of the biology of type 2 inflammation in asthma, examine its influence on type 2 inflammatory comorbidities, and discuss how type 2 inflammatory biomarkers can be harnessed to further personalise treatments in the age of biologic medicines.

\section{Introduction}

Asthma is associated with significant heterogeneity. Several different asthma phenotypes with unique clinical and inflammatory profiles have now been identified. The 2020 Global Initiative for Asthma (GINA) guidelines recommend assessment of inflammatory phenotypes in patients with severe asthma because these profiles can help describe the physical manifestation of airway inflammation and may also help predict responsiveness to tailored treatments [1, 2]. Table 1 presents an example of current asthma phenotypes as they relate to inflammatory type (type 2-high or type 2-low) and phenotypic characteristics. Hallmarks of type 2 pathway activation include IgE production, eosinophilia and elevated type 2 biomarkers such as fraction of exhaled nitric oxide $\left(F_{\text {eNO }}\right)$. Endotypes help to further elucidate the heterogeneity within asthma by identifying subtypes of the condition based on distinct functional or pathophysiological characteristics [12-14]. Unlike phenotypes, which may change over time or in response to treatment, endotype subgroups remain relatively stable because they are defined by inherent genetic and molecular mechanisms [15]. 
TABLE 1 Type 2 inflammation and phenotypic characteristics of asthma [3-5]

Blood eosinophilia ( $\geqslant 150$ cells $\left.\mu \mathrm{L}^{-1}[6]\right)$

Elevated tissue eosinophilia

Elevated serum IgE (surpassing the normal range of $\left.1.5-114 \mathrm{kU} \cdot \mathrm{L}^{-1 \#}[9,10]\right)$

Elevated $F_{\mathrm{eNO}}(>19.5 \mathrm{ppb}[11])$

Upper airway comorbidities, including AR and CRSsNP/CRSwNP

Other type 2 comorbidities, including EOE and $A D$

Responsive to corticosteroids

IL: interleukin; Ig: immunoglobulin; $F_{\mathrm{eNO}}$ : fraction of exhaled nitric oxide; AR: allergic rhinitis; CRSsNP: chronic rhinosinusitis without nasal polyps; CRSwNP: chronic rhinosinusitis with nasal polyps; EoE: eosinophilic oesophagitis; AD: atopic dermatitis. \#: value within the normal range does not exclude atopy [10].

Asthma and associated type 2 inflammation are observed in $50-70 \%$ of patients with asthma, and are driven by both the innate (type 2 innate lymphoid (ILC2) cells) and adaptive (T-helper cell type 2 (Th2) cells) immune systems, characterised by the release of cytokines such as interleukin (IL)-4, IL-5 and IL-13, key pathophysiological characteristics of asthma [3, 13]. IL-4 and IL-13 are involved in mucus production and goblet cell hyperplasia, airway smooth muscle contractility and proliferation, fibrosis, basement membrane thickening, barrier dysfunction, eosinophil trafficking into the lungs and IgE production [16]. IL-5 promotes eosinophil maturation, activation and trafficking [16]. IgE then promotes the degranulation of mast cells and basophils, and the development of allergic reactions in asthma. Elevations in inflammatory cells and biomarkers downstream of type 2 cytokines, including $F_{\text {eNO}}$, serum IgE and blood and sputum eosinophils, have been linked to mechanisms involved in type 2 inflammation [17].

Targeting specific cytokines within the type 2 inflammatory pathway reduces the pathophysiology of asthma and other type 2 inflammatory comorbidities [13]. A number of targeted biologics have been evaluated as potential treatments, including monoclonal antibodies to IL-4, IL-5, IgE and IL-13; in the process, insights have been provided into the molecular mechanisms of these atopic diseases [18-20]. Current GINA guidelines recommend blockade of the IL-4 receptor (IL-4R) (thus inhibiting signalling of both IL-4 and IL-13) in patients with severe type 2/eosinophilic asthma, inhibition of IgE in patients with severe allergic asthma, and inhibition of IL-5/blockade of the IL-5 receptor (IL-5R) in patients with severe eosinophilic asthma (figure 1) [2, 21]. Biomarkers that reflect type 2 cytokine involvement are currently being used for personalised treatment or patient selection in clinical trials of a number of these targeted biologics [13].

This review discusses our current understanding of the biology of type 2 inflammation in asthma, its influence on type 2 inflammatory comorbidities and how type 2 inflammatory biomarkers can be harnessed to further personalise treatments in the age of biologic medicines.

\section{The impact of type 2 cytokines on the pathophysiological features of asthma}

Type 2 inflammatory airway disease can be associated with debilitating symptoms, greater requirement for corticosteroid medication, suboptimal disease control and poor quality of life. The characteristic pathological features of type 2 asthma, as outlined above, include cytokine-induced eosinophilic airway inflammation, mucus plugging, goblet cell hyperplasia, changes in epithelial barrier and airway smooth muscle function, and remodelling of the airway wall (table 2) [16, 23]. In this section, we discuss each of the features in turn, highlighting the key drivers and cytokines involved.

\section{Inflammatory response}

The interplay between innate and adaptive cells and mediators in type 2 inflammation underpins asthma pathophysiology (figure 2) [3, 16, 24]. Type 2 immune responses in the airway are mediated mainly by eosinophils, mast cells, basophils, Th2 cells, ILC2s and IgE-producing B-cells. Upstream events in the airway epithelium involving secretion of master regulators or alarmins such as IL-33, IL-25 or thymic stromal lymphopoietin (TSLP) regulate maturation of $\mathrm{CD}^{+}$T-cells to induce a Th2 adaptive immune response. Th2 cells migrate to the airway epithelium, where, together with ILC2 cells, they generate a variety of type 2 cytokines (IL-4, IL-5 and IL-13) that aid in eosinophil recruitment and B-cell class switching $[13,24]$. These cytokines play key roles in the disease pathophysiology and drive a variety of downstream events, including activation of airway epithelial cells, chemoattraction of effector cells, 


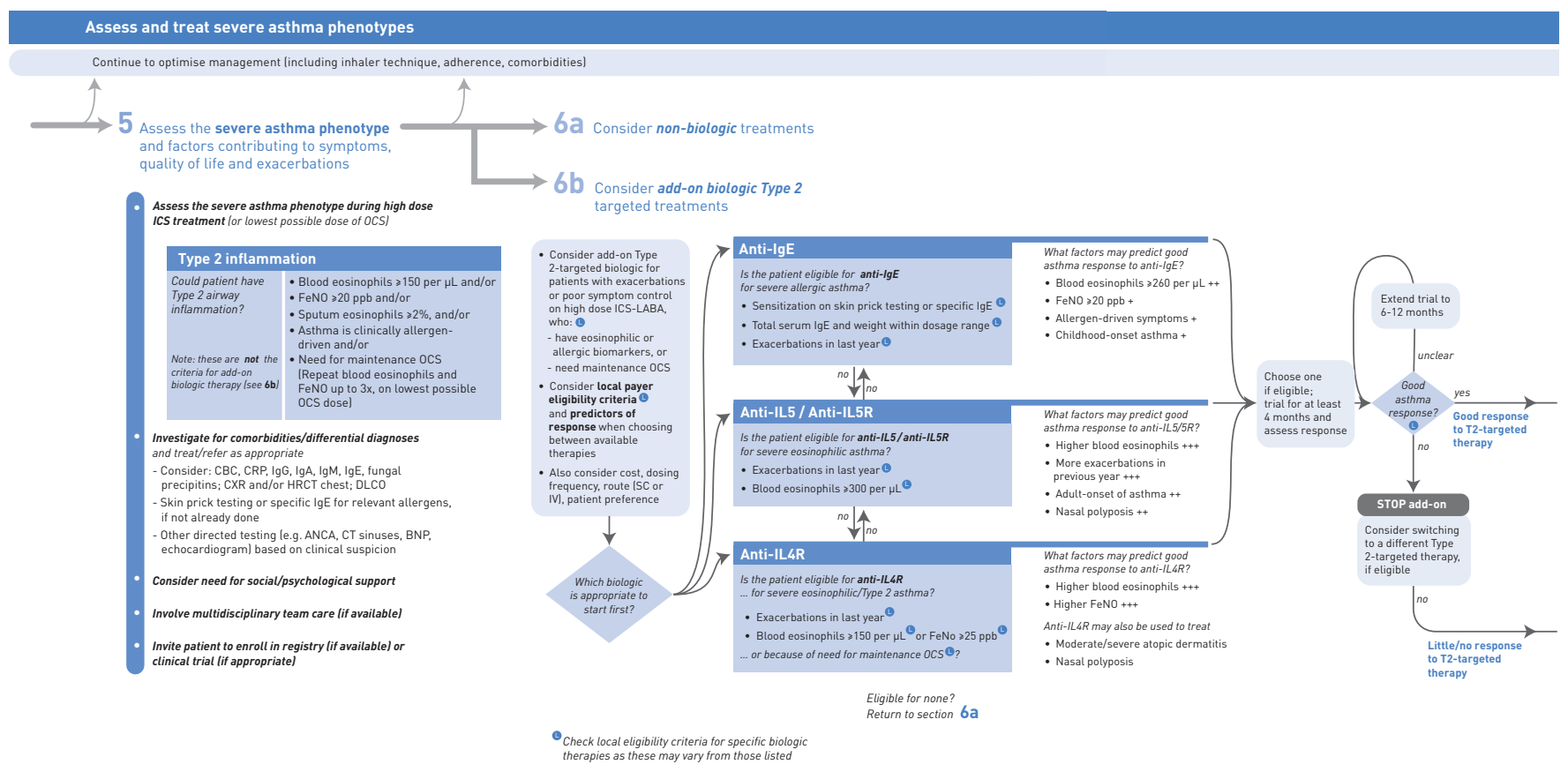

FIGURE 1 GINA guidelines for the assessment of adult and adolescent patients with difficult-to-treat asthma including biologic treatment options. C 2020 Global Initiative for Asthma, reprinted with permission (www.ginasthma.org). ANCA: antineutrophil cytoplasmic antibody; BNP: B-type natriuretic peptide; CBC: complete blood count; CRP: C-reactive protein; CT: computerised tomography; CXR: chest X-ray; DLCO: diffusing capacity of the lung for carbon monoxide; FeNO: fractional exhaled nitric oxide; HRCT: high-resolution computerised tomography; ICS: inhaled corticosteroids; Ig: immunoglobulin; IL: interleukin; IV: intravenous; LABA: long-acting $\beta 2$-agonist; OCS: oral corticosteroids; SC: subcutaneous.

regulation of airway smooth muscle and remodelling of the epithelial matrix. These responses, in turn, predispose towards hyperresponsiveness, airflow obstruction and exacerbations. In addition to the adaptive response to external stimuli, IL-25, IL-33 and TSLP can directly activate ILC2s to secrete IL-5, IL-13 and IL-9, the latter contributing to the further activation and survival of ILC2s [25, 26]. In vitro studies have shown that IL-4 and IL-13 can induce B-cell switching and IgE production, leading to the sensitisation of mast cells and basophils and consequent release of pro-inflammatory mediators such as type 2 cytokines (IL-4, IL-5 and IL-13), histamine, leukotrienes and prostaglandin $\mathrm{D}_{2}$ upon allergen exposure [16]. The overlapping functions of IL-4 and IL-13 may be due to receptor and cytokine expression patterns, because both cytokines signal through two potentially heterodimeric receptors with a shared receptor moiety, the IL-4R $\alpha$ chain [27].

The central clinical role of IL-4 and IL-13 in type 2 inflammation is recognised in the current GINA guidelines, which recommend blockade of IL-4R $\alpha$, the shared receptor component for IL-4 and IL-13, in the treatment of patients with severe type 2 asthma (as well as atopic dermatitis (AD) or chronic rhinosinusitis with nasal polyps (CRSwNP). By contrast, anti-IgE and anti-IL-5/anti-IL-5R antibodies are used as targeted therapies against components of type 2 inflammation and they are restricted to use in patients with severe allergic asthma and eosinophilic asthma, respectively (figure 1) [2, 21].

\section{Epithelial barrier function and epithelium-derived cytokines}

Epithelial barrier dysfunction in response to chronic airway injury is a pathophysiological feature shared across type 2 inflammatory airway diseases. Disruption of the epithelial barrier allows environmental agents (e.g. airway viruses, allergens, bacteria and fungi) to penetrate the epithelium and activate innate and adaptive immune responses, resulting in histological changes and functional abnormalities in the airway mucosal epithelium. The release of epithelium-derived cytokines such as TSLP, IL-25 and IL-33 from bronchial and nasal epithelial cells contributes to the overall pathophysiology of asthma, and the damage to barrier function increases mucosal permeability to foreign substances [28]. Epithelium-derived cytokines recruit dendritic cells and promote their maturation; they in turn activate T-cells via antigen presentation and co-stimulation [29]. They also act as chemoattractants for eosinophils and neutrophils, and secretion of TSLP, IL-25 and IL-33 can further stimulate the production of key type 2 cytokines (i.e. IL-4, 
TABLE 2 Key cytokines that directly promote pathological features of asthma in murine models of asthma [22]

\begin{tabular}{ll} 
Feature & Cytokines \\
\hline Eosinophilia & $\mathrm{IL}-4$, IL-5, IL-13 \\
Goblet cell metaplasia & $\mathrm{IL}-4$, IL-13 \\
Airway hyperresponsiveness & $\mathrm{IL}-4$, IL-13, IL-17A \\
IgE production & $\mathrm{IL}-4$, IL-13 \\
Mastocytosis & $\mathrm{IL}-3$, IL-9 \\
Alternative macrophage activation & $\mathrm{IL}-4$, IL-13 \\
Smooth muscle remodelling & $\mathrm{IL}-4$, IL-13 \\
Th2 induction and maintenance & $\mathrm{IL}-4$, IL-9, IL-17E, IL-25, IL-33, TSLP \\
Sub-epithelial fibrosis & $\mathrm{IL}-4$, IL-13, TGF- $\beta$ \\
\hline
\end{tabular}

IL: interleukin; Th2: T-helper cell type 2; TSLP: thymic stromal lymphopoietin; TGF: transforming growth factor.

IL-5 and IL-13) in inflammatory cells of the innate (ILC2s) and adaptive (Th2 cells) arms of the immune system [3, 30]. These cytokines contribute to epithelial barrier disruption, increasing epithelial permeability [31, 32]. Additionally, release of IL-13 by ILC2s stimulates epithelial cells to increase IL-33 production, resulting in a positive feed-forward loop [33]. Exposure of human bronchial epithelial cells to IL-4 and IL-13 in vitro substantially impairs the airway epithelial cell junctional complex structure and function in a Janus kinase-dependent manner. This suggests that Th2-cytokine-dependent barrier disruption may underlie the observed defects in barrier function seen in allergic asthma [31]. Disruption of bronchial epithelial tight junction barrier proteins by IL-13 in in vivo studies highlights another essential mechanism of asthma pathogenesis [32].

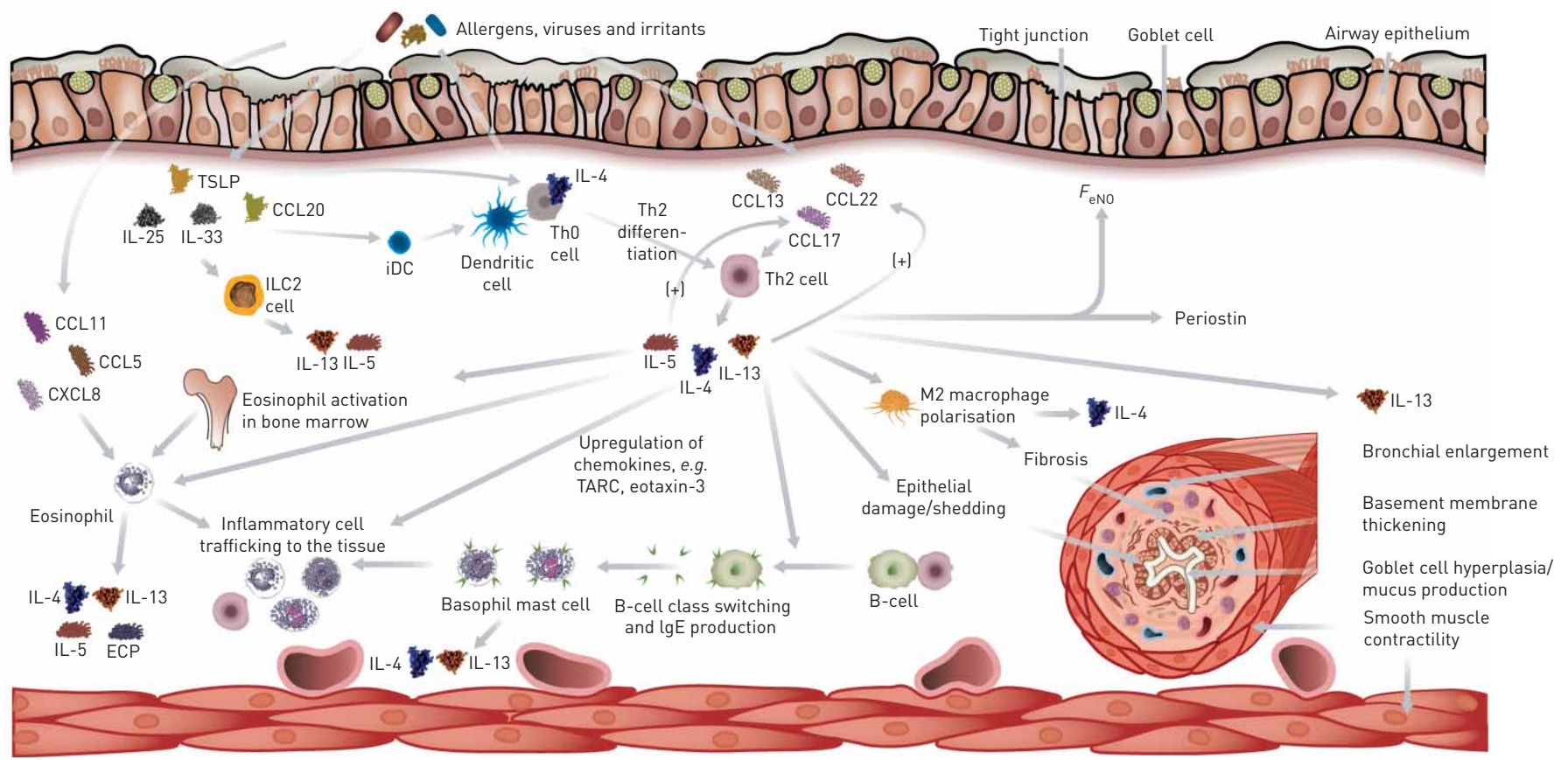

FIGURE 2 The interplay between innate and adaptive cells and mediators in type 2 inflammation underpins asthma pathophysiology. Disruption of the epithelium allows penetration by allergens, viruses or bacteria, activating innate and adaptive immune responses. Presentation of antigens by dendritic cells activates naïve T-helper cells (T-helper cell type 0 (Th0) cells) to differentiate into T-helper cell type 2 (Th2) cells, which in turn produce interleukin (IL)-4, leading to further differentiation of Th0 cells. Cytokines released by Th2 cells lead to eosinophil activation and trafficking of inflammatory cells, B-cell class switching and changes to the airway, including basement membrane thickening, bronchial enlargement, goblet cell hyperplasia and fibrosis. $\mathrm{CCL}$ : chemokine (C-C motif) ligand; $\mathrm{CXCL}$ : chemokine (C-X-C motif) ligand; ECP: eosinophil cationic protein; $F_{\text {eNo: }}$ fraction of exhaled nitric oxide; iDC: interstitial dendritic cell; ILC2: type 2 innate lymphoid cell; TARC: thymus and activation-regulated chemokine; TSLP: thymic stromal lymphopoietin. 
Similar results have also been observed with other pro-inflammatory cytokines (including tumor necrosis factor- $\alpha$ and interferon- $\gamma$ ) that disrupt the tight junction of human airway epithelium and promote inflammatory cytokine release [34]. Epithelial barrier fragility is also strongly associated with the release of epithelial cytokines, TSLP, IL-25 and IL-33, due to the activation of airway epithelial cells, dendritic cells and ILC2s [28].

\section{Mucus secretion}

The role of mucus plugging of the airways in the pathophysiology of asthma has long been recognised [35]. The principal cause of death from asthma is asphyxiation from profound airflow obstruction, which likely includes intraluminal airway obstruction by widespread mucus plugs [36]. Excess mucus production contributes to airflow obstruction [37], and the subsequent formation of mucus plugs is associated with decreased lung function. This pathobiology is commonly observed in patients with severe airflow obstruction.

Mucus metaplasia (i.e. increased surface epithelial mucin production) and an increased number of bronchial microvessels are components of airway remodelling in asthma and are a predisposition to mucus dysfunction [38]. These changes occur in patients with airway inflammation and are characterised by infiltration of the airway wall and luminal mucus with CD4 ${ }^{+}$T-cells, eosinophils and ILC2s that secrete Th2 cytokines [39].

In a mouse model, IL-13 signalling affects goblet cell count following an allergic stimulus and plays a significant role in the generation and persistence of airway inflammation, remodelling and dysfunction [40]. IL-13 also increases production of the glycoprotein mucin 5AC (MUC5AC), which is associated with a more adherent type of mucus, over MUC5B. Changes in mucus composition and organisation are likely to be major contributors to airway obstruction, morbidity and mortality in asthma [36].

\section{Smooth muscle function and airway remodelling}

Airway remodelling is a collective term that represents the multiple pathological changes that occur in the airway epithelium and submucosa and lead to permanent structural changes of the airway in patients with asthma [3]. IL-4 and IL-13 cause changes in the airway mucosa that may predispose patients with asthma to exacerbations by narrowing the baseline airway calibre and altering structural elements that then exaggerate responses to inhaled triggers (figure 3) [3, 16, 41]. IL-5 has also been implicated in epithelial desquamation and airway remodelling [42]. Ongoing inflammation and airway remodelling in asthma also contribute to a self-perpetuating cycle of exacerbations in the exacerbation-prone phenotype [43].

Airway smooth muscle cells express receptors for cytokines derived from CD4 ${ }^{+}$T-cells. These cytokines, particularly IL-13, can act directly on airway smooth muscle cells, leading to changes in contractile and relaxant responses, proliferation and the ability of smooth muscle cells to generate chemokines such as eotaxin and thymus and activation-regulated chemokine (TARC), thus potentiating mitogenic effects [44, 45].

IL-13 facilitates calcium influx (a mechanism that mediates airway smooth muscle contraction) in response to contraction to histamine in human airway smooth muscle cells [44]. IL-13 signalling also affects histological responses and is a key mediator of the tissue fibrosis caused by type 2 inflammation [46, 47]. The fibrogenic effects of IL-13 can be mediated by transforming growth factor- $\beta$ (TGF- $\beta$ ), and IL-13 selectively stimulates TGF- $\beta$ production in Clara cell $10-\mathrm{kDa}$ (CC10)-IL-13 transgenic mice. TGF- $\beta$ antagonists (soluble TGF $\beta$ R-Fc) decrease IL-13-induced lung collagen production in mice [46]. There is also evidence that IL-13 induces sub-epithelial fibrosis through direct effects on fibroblast proliferation and collagen production, both dependent on [48] and independent of [49] TGF- $\beta$. IL-13 also increases fibroblast invasiveness in human airway fibroblasts in patients with asthma [47, 50].

Eosinophils are thought to also play an important role in the airway remodelling process. Epithelialderived cytokines, including chemokine ligands CXCL8, CXCL5 and CCL11, promote the infiltration of eosinophils into the airway tissue [29]. Eosinophils secrete numerous pro-fibrotic molecules, such as eosinophil cationic protein and TGF- 31 , which are key drivers of airway remodelling and pro-inflammatory cytokines (e.g. IL-5) perpetuating the tissue inflammation. In vitro studies have also demonstrated that eosinophils interact with both mast cells and epithelial cells, inducing epithelial secretion of inflammatory cytokines and stimulating mast cells to produce fibrogenic factors as well as tumor necrosis factor- $\alpha$, which further stimulates TGF- $\beta 1$ release from eosinophils [51, 52]. 


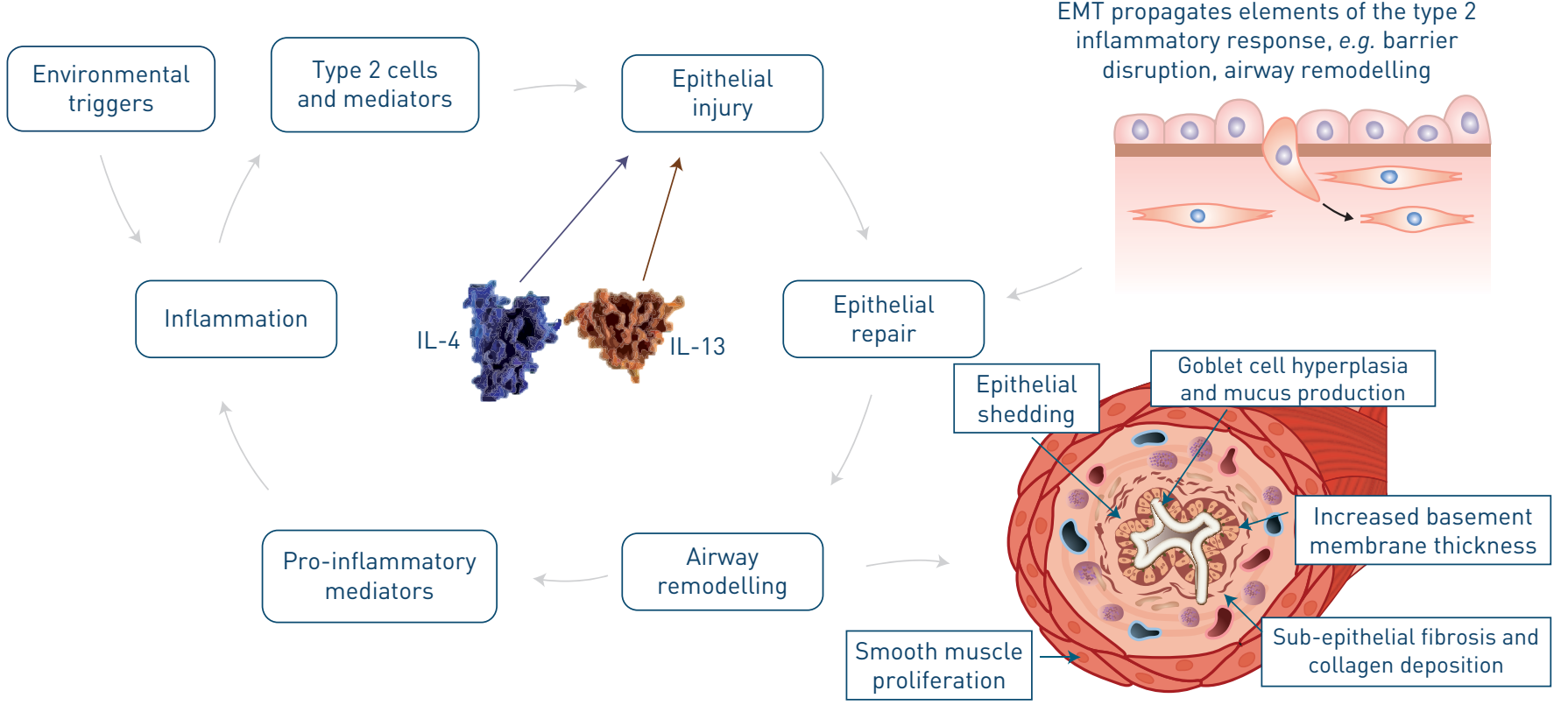

FIGURE 3 Interleukin (IL)-4 and IL-13 are central to airway remodelling. Environmental triggers begin the process of inflammation in the airway with stimulation of type 2 inflammatory cells and mediators, including IL-4 and IL-13, which damage the epithelium. Repair is propagated from the epithelial-mesenchymal transition (EMT), leading to barrier disruption and remodelling of the airway. This remodelling results in epithelial shedding, increased thickness of the basement membrane, fibrosis and collagen deposition, smooth muscle proliferation, goblet cell hyperplasia and mucus production. Additionally, remodelling results in increased pro-inflammatory mediators, which further increase inflammation and epithelial damage.

Common pathophysiological features in type 2 inflammatory comorbidities

Comorbid diseases can interface with type 2 inflammation to enhance existing immune processes of tissue injury. Type 2 inflammation is the unifying feature of uncontrolled, persistent asthma and a number of comorbid inflammatory diseases, including CRSwNP, allergic rhinitis (AR), eosinophilic oesophagitis (EoE) and $\mathrm{AD}$, which can manifest as distinct or comorbid diseases with asthma [16]. The prevalence of common comorbidities varies among inflammatory diseases, with up to $50 \%$ of patients with chronic rhinosinusitis or CRSwNP, up to $60 \%$ with EoE and up to $26 \%$ with AD also having comorbid asthma [53-55]. Similarly, $>80 \%$ of patients with asthma have AR, and up to $40 \%$ of patients with AR have comorbid asthma [56, 57].

Similar to the pathogenesis seen in asthma, CRSwNP, AR, EoE and AD are characterised by an upregulation of type 2 cytokines, IgE-mediated release of immune mediators and dysfunction of epithelial or epidermal barriers [58-63].

Recent asthma and CRSwNP guideline updates recognise the importance of type 2 inflammation and the key type 2 cytokines IL-4, IL-5 and IL-13 in the pathophysiology of these diseases [2, 21, 64]. Targeting these key proximal type 2 cytokines represents a promising strategy to achieve therapeutic benefit across multiple diseases. Efficacy results in recent studies that adopted a personalised approach to treatment suggest that type 2 inflammation is broadly relevant across the severe asthma population if key upstream drivers are blocked effectively; these results support the hypothesis that targeting central pathways could benefit multiple allergic diseases [16]. Type 2 biologic treatments recommended by GINA (asthma) and the European Forum for Research and Education in Allergy and Airway Disease (CRSwNP) reflect the key type 2 cells and mediators in this pathway by targeting IgE, IL-5/IL-5R and IL-4R (figure 2) [21, 64].

\section{Chronic rhinosinusitis with nasal polyps}

Epithelial barrier dysfunction and mucosal deficits contribute to Staphylococcus aureus colonisation of nasal polyps, which then contribute to the development of chronic inflammation in CRSwNP. S. aureus enterotoxins skew the cytokine response towards a type 2 phenotype with increased IL-4, IL-5 and IL-13 expression, which initiates and perpetuates the inflammatory response. These factors combine to drive the 
influx of a variety of immune cells, including eosinophils, mast cells, ILC2s and lymphocytes, all of which participate in chronic inflammatory response within the nasal polyps [16, 38, 65].

\section{Allergic rhinitis}

The inflammatory response in the nasal mucosa in AR includes an early IgE-mediated and a late-phase response that includes recruitment of eosinophils and basophils, and release of type 2 cytokines including IL-4, IL-5 and IL-13 [66]. Chemoattractants, including eotaxin, IL-5 and RANTES (regulated on activation, normal T-cell expressed and secreted), promote the characteristic infiltration by eosinophils, basophils, Th2 lymphocytes and mast cells seen in chronic AR. As our understanding of the basic pathophysiological features of AR evolves, the development of new diagnostic and treatment options may allow more effective modulation of key pathways in the immune system to alter atopic disease processes and associated morbidity [16, 67-69].

\section{Atopic dermatitis}

$\mathrm{AD}$ is a common skin disease characterised by a disturbed skin barrier, susceptibility to cutaneous infections and intractable pruritus [16]. AD provokes Th2-mediated immune responses to numerous environmental antigens, and evidence for type 2 inflammation is found in both acute and chronic skin lesions [70]. IL-4, IL-5 and IL-13 are implicated in the pathogenesis of AD, with increased levels leading to amplified signalling of type 2 cytokines and chemokines, activation of subsequent pro-inflammatory signalling pathways and effects on epidermal barrier function [16, 62]. Patients with $\mathrm{AD}$ also have increased levels of TARC, a chemokine that promotes migration of Th2 cells [71].

What can be learned about underlying type 2 inflammation from measurements of biomarkers? Accurate diagnosis and treatment of asthma, while complicated by the heterogeneous pathophysiology of the disease, are particularly important given the availability of targeted therapies that may only be effective for specific patient subgroups. The identification of biomarkers linked to mechanisms involved in type 2 airway inflammation also has the potential to aid diagnosis and predict and monitor response to treatment [13, 16, 72, 73]. A number of biomarkers of type 2 inflammation have been shown to have potential utility in distinguishing type 2-high versus type 2-low phenotypes and to predict responsiveness to type 2 cytokine-targeted therapy [3]. These type 2-associated biomarkers include $F_{\text {eNo, serum total and }}$ allergen-specific IgE and blood or sputum eosinophil levels [17].

Nitric oxide (NO) is derived endogenously from the amino acid L-arginine and can be measured in exhaled breath as $F_{\text {eNO }}$ via a simple non-invasive procedure that is relatively easy to use in patients with severe airflow obstruction [74]. IL-4 and IL-13 induce NO production from airway epithelia [73]. $F_{\mathrm{eNO}}$ is increasingly recognised as a viable biomarker of type 2 inflammation that reflects corticosteroid-responsive airway inflammation in symptomatic patients and persistence of airway inflammation despite use of inhaled corticosteroids [2, 21, 74-78].

Expression of IL-4 and IL-13 significantly increases NO production from airway epithelia [75]. Patients with asthma with a high $F_{\text {eNO }}$ phenotype $(\geqslant 35 \mathrm{ppb})$ represent a significant proportion of the asthma population, and this sub-phenotype is typified by increased arginine metabolism, and clinically characterised by greater airflow obstruction and airway reactivity [79].

High $F_{\mathrm{eNO}}$ levels in severe asthma have been shown to identify patients with greater airflow limitation and reversibility, higher sputum eosinophils and most emergency department visits and intensive care unit admissions, suggesting that grouping patients with severe asthma by $F_{\text {eNO }}$ identifies the most aggressive asthma phenotype [80].

Elevation in serum IgE is a consequence of IL-4-driven immunoglobulin class switching in B-lymphocytes and is a characteristic feature of atopic diseases [16]. Allergen-specific IgE antibodies also contribute to inflammatory processes in asthma. Currently, the main clinical applications of this biomarker are to estimate the optimal dosage of the anti-IgE antibody omalizumab [81] for add-on treatment in severe allergic asthma, and to support screening for allergic bronchopulmonary aspergillosis, a condition that is often accompanied by very high serum total IgE [82].

As discussed, eosinophils are key cellular effectors of type 2 inflammation and play a major role in maintaining long-term inflammation in asthma. Eosinophils can be measured in peripheral blood, lung tissue and airway lumen (sputum) using various techniques; however, invasive procedures such as tissue biopsies and assessment in induced sputum are not available in routine clinical practice except in very few academic centres. Hence, measurement of peripheral blood eosinophils is more widely used in clinical 
practice [83]. Clinical studies have demonstrated correlations between blood eosinophil levels and asthma-related outcomes such as risk of severe exacerbations and asthma control levels [84]. Additionally, clinical trials of biologic treatments for asthma have frequently shown that treatment responses are higher in patients with high levels of blood eosinophils at baseline and are therefore at least partially predictive of treatment response [85]. Studies have shown that sputum eosinophil-guided asthma management can reduce the frequency of exacerbations when a cut-off of $>3 \%$ sputum eosinophils is used and suggest that this measure is a sensitive and reliable biomarker to guide treatment [13]. Eosinophils contribute to immune response modulation, airway hyperresponsiveness and remodelling, and synergistically interact with IL-4, IL-5, IL-13 and other inflammatory mediators to facilitate their accumulation in the lungs [86].

\section{Therapeutic implications}

Type 2 cytokines have integral roles in the pathogenesis of asthma, and a number of targeted biologics have been evaluated as potential treatments, including those that target IL-4, IL-5 and IL-13 pathways. Currently available monoclonal antibodies include omalizumab (anti-IgE); mepolizumab, reslizumab and benralizumab (anti-IL-5 pathway); and dupilumab (anti-IL-4/IL-13) (table 3). The major benefit of these new biologic agents has been in achieving disease control, as evidenced by significant reductions in exacerbations observed in clinical studies [18]. The relative efficacy of these agents correlates with target selection and the molecular characteristics of the inhibitor. Anti-IgE and anti-IL-5 agents that target downstream mediators of the type 2 pathway are effective in treating asthma and, although not currently approved, CRSwNP, but not AD. Dual blockade of IL-4 and IL-13 has demonstrated significant efficacy across multiple allergic diseases (asthma, AD, CRSwNP, EoE), confirming the commonality of the IL-4/ IL-13 pathway in these atopic diseases [16, 94].

In patients with severe asthma, underlying type 2 airway inflammation may be identified, according to GINA, on the basis of elevated type 2 inflammatory biomarkers (blood and/or sputum eosinophils and/or $\left.F_{\text {eNO}}\right)$ and/or asthma that is clinically allergen driven and/or requires maintenance oral corticosteroids (figure 1) [2, 21, 78].

Biomarkers that reflect the characteristics of the underlying inflammatory process and the presence of type 2 inflammation are currently used to stratify patients in clinical trials for a number of these agents. Accurate classification of a type 2-high asthma phenotype requires a combination of clinical parameters such as allergic phenotype or responsiveness to corticosteroids, as well as type 2 biomarkers, alone or in combination [13].

TABLE 3 Type 2-directed therapies based on monoclonal antibodies: key clinical trials in asthma

\begin{tabular}{|c|c|c|c|c|}
\hline Th2 & Drug & Patient characteristics and biomarkers & Main response & Reference \\
\hline Free IgE & Omalizumab & $\begin{array}{l}\text { Severe asthma on ICS+LABA; atopic status; } \\
\text { serum IgE } 30-700 \mathrm{IU} \cdot \mathrm{mL}^{-1} \text { (USA, age } \\
\text { ₹12 years), } 30-1300 \mathrm{IU} \cdot \mathrm{mL}^{-1} \text { (USA, age } \\
\text { 6-11 years), } 30-1500 \mathrm{IU} \cdot \mathrm{mL}^{-1} \text { (EU) }\end{array}$ & $\begin{array}{l}\text { Reduced asthma exacerbations } \\
\text { Reduction in maintenance OCS }\end{array}$ & [19] \\
\hline $\begin{array}{l}\text { IL-4 receptor } \\
\text { IL-13 }\end{array}$ & Dupilumab & $\begin{array}{l}\text { Moderate-to-severe-uncontrolled asthma; } \\
\mathrm{FEV}_{1} \text { reversibility, persistent symptoms } \\
(\text { ACQ5 } \geqslant 1.5) \text {; exacerbation in past year }\end{array}$ & $\begin{array}{l}\text { Decrease in asthma exacerbations } \\
{\text { Improvement in } \mathrm{FEV}_{1} \text { and } \% \text { change }}^{\text {in } \mathrm{FEV}_{1}} \\
\text { Reduction in maintenance OCS }\end{array}$ & {$[87,88]$} \\
\hline IL-5 & Mepolizumab & $\begin{array}{l}\text { Severe asthma on ICS and } \mathrm{LABA} \pm \mathrm{OCS} \text {; } \\
\text { blood eosinophils } \geqslant 150 \mathrm{~mm}^{-3} \text { at } \\
\text { screening or } \geqslant 300 \mathrm{~mm}^{-3} \text { in past year }\end{array}$ & $\begin{array}{l}\text { Reduced exacerbation rates } \\
\text { Reduction in maintenance OCS } \\
\text { Improvement in } \mathrm{FEV}_{1}\end{array}$ & {$[89,90]$} \\
\hline IL-5 & Reslizumab & $\begin{array}{l}\text { Inadequately controlled, } \\
\text { moderate-to-severe eosinophilic asthma } \\
\left(\geqslant 400 \text { cells } \mu \mathrm{L}^{-1} \text { during screening) }\right.\end{array}$ & $\begin{array}{l}\text { Decrease in asthma exacerbations } \\
\text { Improvement in } \mathrm{FEV}_{1}\end{array}$ & [91] \\
\hline
\end{tabular}

Th2: T-helper cell type 2; Ig: immunoglobulin; ICS: inhaled corticosteroids; LABA: long-acting $\beta_{2}$-agonist; OCS: oral corticosteroids; IL: interleukin; $\mathrm{FEV}_{1}$ : forced expiratory volume in $1 \mathrm{~s}$; ACQ-5: 5-item Asthma Control Questionnaire. 
Given the complexity of inflammatory pathways in asthma, there is likely to be considerable overlap in these biomarkers in each of the asthma phenotypes; consequently, there may be more than one dominant biomarker. Panels of type 2 biomarkers may more accurately reflect risks in asthma, and ultimately help physicians to select the most appropriate treatment. Two separate studies have shown that elevated levels of both $F_{\text {eNO }}$ and blood eosinophils are associated with greater bronchial hyperresponsiveness and increased exacerbations $[95,96]$.

\section{Conclusions}

Type 2 inflammation encompasses multiple asthma phenotypes and drives the key pathophysiological characteristics of asthma and comorbid conditions. Integrated efforts to improve disease understanding signal a trend towards a more disease biology-based approach, wherein clinical, cellular and molecular aspects of the disease are examined together to better identify correlations between clinical traits and specific disease mechanisms. The use of biomarkers linked to mechanisms involved in type 2 inflammation has the potential to improve diagnosis and treatment selection and provides a rational basis for new and personalised treatments targeting specific type 2 inflammatory pathway cytokines.

Acknowledgements: The authors would like to thank Dianne Barry, Colin Mitchell and Ledia Goga of Sanofi and Nora Crikelair of Regeneron Pharmaceuticals, Inc. for their critical feedback during manuscript development. The authors received writing/editorial support in the preparation of this manuscript from Jennifer L.F. Port of Excerpta Medica, funded by Sanofi Genzyme and Regeneron Pharmaceuticals, Inc.

Conflict of interest: W.W. Busse reports personal fees for consultancy from GlaxoSmithKline and personal fees from Novartis, Regeneron Pharmaceuticals, Inc. and Sanofi, during the conduct of the study. M. Kraft reports grants from American Lung Association, AstraZeneca, Chiesi, National Institutes of Health, Regeneron Pharmaceuticals, Inc. and Sanofi, and other (consultancy) from AstraZeneca, Regeneron Pharmaceuticals, Inc. and Sanofi during the conduct of the study; and other (royalties) from Elsevier, outside the submitted work. K.F. Rabe reports personal fees for consultancy and lectures and other from AstraZeneca, Boehringer Ingelheim, Novartis, Sanofi and Teva, during the conduct of the study. Y. Deniz is an employee and shareholder of Regeneron Pharmaceuticals, Inc. P.J. Rowe is an employee and may hold stock/options in Sanofi. M. Ruddy is an employee and shareholder of Regeneron Pharmaceuticals, Inc. M. Castro reports grants from American Lung Association, AstraZeneca, Boehringer Ingelheim, Chiesi, National Institutes of Health, Novartis, PCORI and Sanofi, other (consultancy) from 4D Pharma, Aviragen Therapeutics, Boston Scientific, Genentech, Nuvaira, Sanofi, Teva, Therabron Therapeutics, Theravance Biopharma, Vectura and Vida Pharma, personal fees for lectures from AstraZeneca, Boehringer Ingelheim, Boston Scientific, Genentech, Sanofi, Regeneron Pharmaceuticals, Inc. and Teva, and other (royalties) from Elsevier, during the conduct of the study.

Support statement: This work was supported by Sanofi and Regeneron Pharmaceuticals, Inc. Funding information for this article has been deposited with the Crossref Funder Registry.

\section{References}

1 Corren J. Asthma phenotypes and endotypes: an evolving paradigm for classification. Discov Med 2013; 15: 243-249.

2 Global Initiative for Asthma. Difficult-to-Treat and Severe Asthma in Adolescents and Adult Patients: Diagnosis and Management. www.ginasthma.org/wp-content/uploads/2019/04/GINA-Severe-asthma-PocketGuide-v2.0-wms-1.pdf Date last accessed: August 25, 2020.

3 Fahy JV. Type 2 inflammation in asthma-present in most, absent in many. Nat Rev Immunol 2015; 15: 57-65.

4 Wenzel SE. Asthma phenotypes: the evolution from clinical to molecular approaches. Nat Med 2012; 18: 716-725.

5 Gauthier M, Ray A, Wenzel SE. Evolving concepts of asthma. Am J Respir Crit Care Med 2015; 192: 660-668.

6 Kuruvilla ME, Lee FE, Lee GB. Understanding asthma phenotypes, endotypes, and mechanisms of disease. Clin Rev Allergy Immunol 2019; 56: 219-233.

7 Arron JR, Choy DF, Laviolette M, et al. Disconnect between sputum neutrophils and other measures of airway inflammation in asthma. Eur Respir J 2014; 43: 627-629.

8 Carr TF, Zeki AA, Kraft M. Eosinophilic and noneosinophilic asthma. Am J Respir Crit Care Med 2018; 197: 22-37.

9 Zetterström O, Johansson SG. IgE concentrations measured by PRIST in serum of healthy adults and in patients with respiratory allergy. A diagnostic approach. Allergy 1981; 36: 537-547.

10 Carosso A, Bugiani M, Migliore E, et al. Reference values of total serum IgE and their significance in the diagnosis of allergy in young European adults. Int Arch Allergy Immunol 2007; 142: 230-238. 
11 Holguin F, Cardet JC, Chung KF, et al. Management of severe asthma: a European Respiratory Society/ American Thoracic Society guideline. Eur Respir J 2020; 55: 1900588.

12 Wenzel SE. Emergence of biomolecular pathways to define novel asthma phenotypes: type-2 immunity and beyond. Am J Respir Cell Mol Biol 2016; 55: 1-4.

13 Robinson D, Humbert M, Buhl R, et al. Revisiting type 2-high and type 2-low airway inflammation in asthma: current knowledge and therapeutic implications. Clin Exp Allergy 2017; 47: 161-175.

14 Svenningsen S, Nair P. Asthma endotypes and an overview of targeted therapy for asthma. Front Med (Lausanne) 2017; 4: 158.

15 Green RH, Pavord I. Stability of inflammatory phenotypes in asthma. Thorax 2012; 67: 665-667.

16 Gandhi NA, Bennett BL, Graham NMH, et al. Targeting key proximal drivers of type 2 inflammation in disease. Nat Rev Drug Discov 2016; 15: 35-50.

17 Kim MA, Shin YS, Pham LD, et al. Adult asthma biomarkers. Curr Opin Allergy Clin Immunol 2014; 14: 49-54.

18 Busse WW. Biological treatments for severe asthma: a major advance in asthma care. Allergol Int 2019; 68: 158-166.

19 McGregor MC, Krings JG, Nair P, et al. Role of biologics in asthma. Am J Respir Crit Care Med 2019; 199: 433-445.

20 Krings JG, McGregor MC, Bacharier LB, et al. Biologics for severe asthma: treatment-specific effects are important in choosing a specific agent. J Allergy Clin Immunol Pract 2019; 7: 1379-1392.

21 Global Initiative for Asthma. Pocket Guide for Asthma Management and Prevention. www.ginasthma.org/ wp-content/uploads/2019/04/GINA-2019-main-Pocket-Guide-wms.pdf Date last accessed: August 25, 2020.

22 Finkelman FD, Hogan SP, Hershey GK, et al. Importance of cytokines in murine allergic airway disease and human asthma. J Immunol 2010; 184: 1663-1674.

23 Schleimer RP. Immunopathogenesis of chronic rhinosinusitis and nasal polyposis. Annu Rev Pathol 2017; 12 : 331-357.

24 Dunican EM, Fahy JV. The role of type 2 inflammation in the pathogenesis of asthma exacerbations. Ann Am Thorac Soc 2015; 12: Suppl. 2, S144-S149.

25 van Rijt L, von Richthofen H, van Ree R. Type 2 innate lymphoid cells: at the cross-roads in allergic asthma. Semin Immunopathol 2016; 38: 483-496.

26 Gurram RK, Zhu J. Orchestration between ILC2s and Th2 cells in shaping type 2 immune responses. Cell Mol Immunol 2019; 16: 225-235.

27 Gandhi NA, Pirozzi G, Graham NMH. Commonality of the IL-4/IL-13 pathway in atopic diseases. Expert Rev Clin Immunol 2017; 13: 425-437.

28 Gon Y, Hashimoto S. Role of airway epithelial barrier dysfunction in pathogenesis of asthma. Allergol Int 2018; 67: 12-17.

29 Liu C, Zhang X, Xiang Y, et al. Role of epithelial chemokines in the pathogenesis of airway inflammation in asthma (Review). Mol Med Rep 2018; 17: 6935-6941.

30 Bartemes KR, Kita H. Dynamic role of epithelium-derived cytokines in asthma. Clin Immunol 2012; 143: 222-235.

31 Saatian B, Rezaee F, Desando S, et al. Interleukin-4 and interleukin-13 cause barrier dysfunction in human airway epithelial cells. Tissue Barriers 2013; 1: e24333.

32 Sugita K, Steer CA, Martinez-Gonzalez I, et al. Type 2 innate lymphoid cells disrupt bronchial epithelial barrier integrity by targeting tight junctions through IL-13 in asthmatic patients. J Allergy Clin Immunol 2018; 141: 300-310.

33 Christianson CA, Goplen NP, Zafar I, et al. Persistence of asthma requires multiple feedback circuits involving type 2 innate lymphoid cells and IL-33. J Allergy Clin Immunol 2015; 136: 59-68.

34 Hardyman MA, Wilkinson E, Martin E, et al. TNF- $\alpha$-mediated bronchial barrier disruption and regulation by src-family kinase activation. J Allergy Clin Immunol 2013; 132: 665-675.

35 Fahy JV, Dickey BF. Airway mucus function and dysfunction. N Engl J Med 2010; 363: 2233-2247.

36 Bonser LR, Zlock L, Finkbeiner W, et al. Epithelial tethering of MUC5AC-rich mucus impairs mucociliary transport in asthma. J Clin Invest 2016; 126: 2367-2371.

37 Dunican EM, Elicker BM, Gierada DS, et al. Mucus plugs in patients with asthma linked to eosinophilia and airflow obstruction. J Clin Invest 2018; 128: 997-1009.

38 Bergeron C, Al-Ramli W, Hamid Q. Remodeling in asthma. Proc Am Thorac Soc 2009; 6: 301-305

39 National Heart, Lung, and Blood Institute. Guidelines for the Diagnosis and Management of Asthma (EPR-3). Bethesda, MD, National Heart, Lung, and Blood Institute, 2007. www.nhlbi.nih.gov/health-topics/guidelinesfor-diagnosis-management-of-asthma Date last accessed: August 25, 2020.

40 Tomlinson KL, Davies GCG, Sutton DJ, et al. Neutralisation of interleukin-13 in mice prevents airway pathology caused by chronic exposure to house dust mite. PLOS One 2010; 5: e13136.

41 Schleimer RP, Berdnikovs S. Etiology of epithelial barrier dysfunction in patients with type 2 inflammatory diseases. J Allergy Clin Immunol 2017; 139: 1752-1761. 
42 Pelaia C, Paoletti G, Puggioni F, et al. Interleukin-5 in the pathophysiology of severe asthma. Front Physiol 2019; 10: 1514.

43 Dougherty RH, Fahy JV. Acute exacerbations of asthma: epidemiology, biology and the exacerbation-prone phenotype. Clin Exp Allergy 2009; 39: 193-202.

44 Risse P-A, Jo T, Suarez F, et al. Interleukin-13 inhibits proliferation and enhances contractility of human airway smooth muscle cells without change in contractile phenotype. Am J Physiol Lung Cell Mol Physiol 2011; 300: L958-L966.

45 Vatrella A, Fabozzi I, Calabrese C, et al. Dupilumab: a novel treatment for asthma. J Asthma Allergy 2014; 7: 123-130.

46 Lee CG, Homer RJ, Zhu Z, et al. Interleukin-13 induces tissue fibrosis by selectively stimulating and activating transforming growth factor $\beta_{1}$. J Exp Med 2001; 194: 809-821.

47 Ingram JL, Slade D, Church TD, et al. Role of matrix metalloproteinases-1 and -2 in interleukin-13-suppressed elastin in airway fibroblasts in asthma. Am J Respir Cell Mol Biol 2016; 54: 41-50.

48 Firszt R, Francisco D, Church TD, et al. Interleukin-13 induces collagen type-1 expression through matrix metalloproteinase- 2 and transforming growth factor- $\beta_{1}$ in airway fibroblasts in asthma. Eur Respir J 2014; 43: 464-473.

49 Kavirante $\mathrm{M}$, Hesse $\mathrm{M}$, Leusink $\mathrm{M}$, et al. IL-13 activates a mechanism of tissue fibrosis that is completely TGF- $\beta$ independent. J Immunol 2004; 173: 4020-4029.

50 Ingram JL, Huggins MJ, Church TD, et al. Airway fibroblasts in asthma manifest an invasive phenotype. Am J Respir Crit Care Med 2011; 183: 1625-1632.

51 Venge P. The eosinophil and airway remodelling in asthma. Clin Respir J 2010; 4: Suppl. 1, 15-19.

52 Kariyawasam HH, Robinson DS. The role of eosinophils in airway tissue remodelling in asthma. Curr Opin Immunol 2007; 19: 681-686.

53 Vandeplas G, Khan A, Huynh TMT, et al. The 'GA²LEN Sinusitis Cohort': an introduction. Clin Transl Allergy 2015; 5: Suppl. 4, 01.

54 Capucilli P, Cianferoni A, Grundmeier RW, et al. Comparison of comorbid diagnoses in children with and without eosinophilic esophagitis in a large population. Ann Allergy Asthma Immunol 2018; 121: 711-716.

55 Silverberg Jl. Comorbidities and the impact of atopic dermatitis. Ann Allergy Asthma Immunol 2019; 123 144-151.

56 Wise SK, Lin SY, Toskala E, et al. International consensus statement on allergy and rhinology: allergic rhinitis. Int Forum Allergy Rhinol 2018; 8: 108-352.

57 Bousquet J, Khaltaev N, Cruz AA, et al. Allergic rhinitis and its impact on asthma (ARIA) 2008. Allergy 2008; 63: Suppl. 86, 8-160.

58 Leung J, Beukema KR, Shen AH. Allergic mechanisms of eosinophilic oesophagitis. Best Pract Res Clin Gastroenterol 2015; 29: 709-720.

59 Suzuki Y, Kodama M, Asano K. Skin barrier-related molecules and pathophysiology of asthma. Allergol Int 2011; 60: 11-15.

60 Zhang Y, Zhou B. Functions of thymic stromal lymphopoietin in immunity and disease. Immunol Res 2012; 52: 211-223.

61 Brandt EB, Sivaprasad U. Th2 cytokines and atopic dermatitis. J Clin Cell Immunol 2011; 2: 110.

62 Eifan AO, Durham SR. Pathogenesis of rhinitis. Clin Exp Allergy 2016; 46: 1139-1151.

63 Kato A. Immunopathology of chronic rhinosinusitis. Allergol Int 2015; 64: 121-130.

64 Fokkens WJ, Lund V, Bachert C, et al. EUFOREA consensus on biologics for CRSwNP with or without asthma. Allergy 2019; 74: 2312-2319.

65 Hulse KE, Stevens WW, Tan BK, et al. Pathogenesis of nasal polyposis. Clin Exp Allergy 2015; 45: 328-346.

66 Pawankar R, Mori S, Ozu C, et al. Overview on the pathomechanisms of allergic rhinitis. Asia Pac Allergy 2011; 1: 157-167.

67 Liu JN, Shin YS, Yoo H-S, et al. The prevalence of serum specific IgE to superantigens in asthma and allergic rhinitis patients. Allergy Asthma Immunol Res 2014; 6: 263-266.

68 Steelant B, Farré R, Wawrzyniak P, et al. Impaired barrier function in patients with house dust mite-induced allergic rhinitis is accompanied by decreased occludin and zonula occludens-1 expression. $J$ Allergy Clin Immunol 2016; 137: 1043-1053.e5.

69 Samitas K, Carter A, Kariyawasam HH, et al. Upper and lower airway remodelling mechanisms in asthma, allergic rhinitis and chronic rhinosinusitis: the one airway concept revisited. Allergy 2018; 73: 993-1002.

70 Gittler JK, Shemer A, Suárez-Fariñas M, et al. Progressive activation of Th2/Th22 cytokines and selective epidermal proteins characterizes acute and chronic atopic dermatitis. J Allergy Clin Immunol 2012; 130: 1344-1354.

71 Hijnen D, De Bruin-Weller M, Oosting B, et al. Serum thymus and activation-regulated chemokine (TARC) and cutaneous $T$ cell-attracting chemokine (CTACK) levels in allergic diseases: TARC and CTACK are disease-specific markers for atopic dermatitis. J Allergy Clin Immunol 2004; 113: 334-340. 
72 Pavord ID, Afzalnia S, Menzies-Gow A, et al. The current and future role of biomarkers in type 2 cytokine-mediated asthma management. Clin Exp Allergy 2017; 47: 148-160.

73 Carr TF, Kraft M. Use of biomarkers to identify phenotypes and endotypes of severe asthma. Ann Allergy Asthma Immunol 2018; 121: 414-420.

74 Dweik RA, Boggs PB, Erzurum SC, et al. An official ATS clinical practice guideline: interpretation of exhaled nitric oxide levels $\left(F_{\mathrm{ENO}}\right)$ for clinical applications. Am J Respir Crit Care Med 2011; 184: 602-615.

75 Spahn JD, Malka J, Szefler SJ. Current application of exhaled nitrous oxide in clinical practice. J Allergy Clin Immunol 2016; 138: 1296-1298.

76 National Institute for Health and Care Excellence. Asthma: Diagnosis, Monitoring and Chronic Asthma Management. www.nice.org.uk/guidance/ng80/resources/asthma-diagnosis-monitoring-and-chronic-asthmamanagement-pdf-1837687975621 Date last accessed: August 14, 2020.

77 Jia G, Erickson RW, Choy DF, et al. Periostin is a systemic biomarker of eosinophilic airway inflammation in asthmatic patients. J Allergy Clin Immunol 2012; 130: 647-654.

78 Global Initiative for Asthma. Global Strategy for Asthma Management and Prevention. www.ginasthma.org/ wp-content/uploads/2020/06/GINA-2020-report_20_06_04-1-wms.pdf Date last accessed: August 25, 2020.

$79 \mathrm{Xu} \mathrm{W,} \mathrm{Comhair} \mathrm{SAA,} \mathrm{Janocha} \mathrm{AJ,} \mathrm{et} \mathrm{al.} \mathrm{Arginine} \mathrm{metabolic} \mathrm{endotypes} \mathrm{related} \mathrm{to} \mathrm{asthma} \mathrm{severity.} \mathrm{PLoS} \mathrm{One}$ 2017; 12: e0183066.

80 Dweik RA, Sorkness RL, Wenzel S, et al. Use of exhaled nitric oxide measurement to identify a reactive, at-risk phenotype among patients with asthma. Am J Respir Crit Care Med 2010; 181: 1033-1041.

81 Xolair. Prescribing Information. 2016. www.gene.com/gene/products/information/pdf/xolair-prescribing.pdf Date last accessed: April 17, 2021.

82 Greenberger PA, Bush RK, Demain JG, et al. Allergic bronchopulmonary aspergillosis. J Allergy Clin Immunol Pract 2014; 2: 703-708.

83 Wadsworth SJ, Sin DD, Dorscheid DR. Clinical update on the use of biomarkers of airway inflammation in the management of asthma. J Asthma Allergy 2011; 4: 77-86.

84 Possa SS, Leick EA, Prado CM, et al. Eosinophilic inflammation in allergic asthma. Front Pharmacol 2013; 4: 46.

85 Kostikas K, Brindicci C, Patalano F. Blood eosinophils as biomarkers to drive treatment choices in asthma and COPD. Curr Drug Targets 2018; 19: 1882-1896.

86 Price DB, Rigazio A, Campbell JD, et al. Blood eosinophil count and prospective annual asthma disease burden: a UK cohort study. Lancet Respir Med 2015; 3: 849-858.

87 Castro M, Corren J, Pavord ID, et al. Dupilumab efficacy and safety in moderate-to-severe uncontrolled asthma. N Engl J Med 2018; 378: 2486-2496.

88 Rabe KF, Nair P, Brusselle G, et al. Efficacy and safety of dupilumab in glucocorticoid-dependent severe asthma. N Engl J Med 2018; 378: 2475-2485.

89 Ortega HG, Liu MC, Pavord ID, et al. Mepolizumab treatment in patients with severe eosinophilic asthma N Engl J Med 2014; 371: 1198-1207.

90 Bel EH, Wenzel SE, Thompson PJ, et al. Oral glucocorticoid-sparing effect of mepolizumab in eosinophilic asthma. N Engl J Med 2014; 371: 1189-1197.

91 Castro M, Zangrilli J, Wechsler ME, et al. Reslizumab for inadequately controlled asthma with elevated blood eosinophil counts: results from two multicentre, parallel, double-blind, randomised, placebo-controlled, phase 3 trials. Lancet Respir Med 2015; 3: 355-366.

92 Bleecker ER, FitzGerald JM, Chanez P, et al. Efficacy and safety of benralizumab for patients with severe asthma uncontrolled with high-dosage inhaled corticosteroids and long-acting $\beta 2$-agonists (SIROCCO): a randomised, multicentre, placebo-controlled phase 3 trial. Lancet 2016; 388: 2115-2127.

93 FitzGerald JM, Bleecker ER, Nair P, et al. Benralizumab, an anti-interleukin-5 receptor $\alpha$ monoclonal antibody, as add-on treatment for patients with severe, uncontrolled, eosinophilic asthma (CALIMA): a randomised, double-blind, placebo-controlled phase 3 trial. Lancet 2016; 388: 2128-2141.

94 Sastre J, Davila D. Dupilumab: a new paradigm for the treatment of allergic diseases. J Investig Allergol Clin Immunol 2018; 28: 139-150.

95 Malinovschi A, Janson C, Borres M, et al. Simultaneously increased fraction of exhaled nitric oxide levels and blood eosinophil counts relate to increased asthma morbidity. J Allergy Clin Immunol 2016; 138: 1301-1308.e2.

96 Price DB, Bosnic-Anticevich S, Pavord ID, et al. Association of elevated fractional exhaled nitric oxide concentration and blood eosinophil count with severe asthma exacerbations. Clin Transl Allergy 2019; 9: 41. 